\title{
Assessing Project Suitability for Off-site Production
}

Nick Blismas (RMIT University, Australia), Alistair Gibb (Department of Civil and Building Engineering, Loughborough University, United Kingdom) and Christine Pasquire (Department of Civil and Building Engineering, Loughborough University, United Kingdom)

\begin{abstract}
Implementation of off-site production on construction projects is often hindered by a number of specific process and procurement constraints. These constraints are largely influenced by decisions within the control of construction clients, suggesting that they have a significant influence over the adoption of off-site production into construction projects. However, an appreciation of the effect of these constraints has been lacking. Addressing this need, an off-site production implementation assessment instrument that resides within a larger toolkit (IMMPREST) was developed using questionnaire survey data and a series of industrial workshops. IMMPREST is an interactive electronic toolkit developed by Loughborough University (UK), in conjunction with eleven industrial partners, which facilitates the evaluation of benefit arising from use of off-site production within construction. It identifies the factors that need to be considered for an evaluation, the data required to assess the effect of these factors, and where the required data resides within the supply chain. Development of the implementation assessment instrument is discussed, whilst also making reference to the role that clients can play in creating the process and procurement conditions that promote rather than constrain the adoption of off-site production.
\end{abstract}

Keywords: drivers, constraints, off-site production, pre-fabrication, toolkit.

\section{INTRODUCTION}

Recent UK government reports, including the Egan Report "Rethinking Construction" (1998), produced by the Construction Task Force, discussed the need for performance improvements in the UK construction industry. Egan (1998) identified standardisation and pre-assembly as having a role in improving construction processes. However, the uptake of off-site production ${ }^{1}$ (OSP) in construction is limited despite the well documented benefits that can be derived from such approaches (Neale et al., 1993; Bottom et al., 1994; CIRIA, 1999, 2000; BSRIA, 1999; Housing Forum, 2002; Gibb and Isack, 2003).

The use of OSP, by many of those involved in the construction process, is poorly understood (CIRIA, 2000). Some view the approach as too expensive to justify its use, whilst others view OSP as the panacea to the ills of the construction industry's manifold problems (Groák, 1992; Gibb, 2001). A pilot study demonstrated that decisions to use OSP are still largely based on anecdotal evidence rather than rigorous data, as no formal measurement procedures or strategies are available (Pasquire and Gibb, 1999). OSP adoption is therefore hindered by the industry's inability to rigorously justify the benefits and adequately identify the constraints peculiar to the approach.

With such uncertainty surrounding the benefits that can be derived from OSP, it is not surprising that clients do not often actively support its implementation in their projects. However, clients have a major, though usually inadvertent, influence on the level and success of OSP implementation on their projects. Their project team and procurement route selections largely determine whether the project environment will be conducive or restrictive to OSP.

To help address these problems of benefit evaluation and constraint identification, a research team at Loughborough University developed an interactive toolkit that facilitates evaluation of benefits and disbenefits arising from OSP within construction. The toolkit development formed part of the 3-year IMMPREST Research Project (Interactive Method for Measuring Pre-assembly and Standardisation Benefit across the Construction Supply Chain), which was funded by the UK Government (Blismas et al., 2003a). Within the funding structure a consortium of eleven industrial collaborators was formed both to steer and provide data for the research. These were drawn from a range of stakeholders, including three leading UK construction clients, a major global contractor, three specialist suppliers and four consultants ranging from quantity surveyors to services and control-systems engineers.

Research undertaken by CIRIA (1999, 2000), prior to this work, identified a series of factors that affect the use of OSP within construction projects. Among these factors were a number identified as constraints to the implementation of OSP. The distribution and effect of these constraints within the industry were, however, ill-understood. As part of IMMPREST a survey was undertaken to understand the effects of these constraints on OSP projects and thereby appreciate the level of influence that these exerted on projects. From these surveys, an OSP implementation assessment instrument (IAI), that forms part of the toolkit, was developed. The instrument is aimed primarily at clients and their advisors, facilitating them to identify the key constraints to OSP implementation on a project. The indicators supplied by the IAI allow the client's team to concentrate on those process and procurement constraints that most inhibit OSP implementation or that will contribute to its poor performance.

Whilst the project drivers frequently seem to be the important factors in decision making, it is the constraints that have the greater potential to affect project outcomes. The IAI uses a penalty point scoring system to evaluate the suitability of OSP for a given project by considering its process and procurement constraints. The effect of this is not only to guide the team during the preproject and pre-construction phases, but also to provide a learning vehicle for future projects. In effect, if OSP is to be used effectively, the constraining factors need to be addressed and disabled by, for example, ensuring that appropriate expertise is available early in the project.

The development of the IAI, which forms a small segment of the toolkit, is discussed in this paper. The next section introduces the work preceding IMMPREST, in which drivers and constraints to OSP adoption were identified. The paper then briefly describes the structure of the IMMPREST toolkit before focusing on the survey and data that informed the development of the IAI. The paper concludes with reference to how the IAI could be used by clients 
to create project environments conducive to OSP adoption and success.

\section{BENEFIT EVALUATION TOOLKIT}

The need for the toolkit grew from a recognition that the industry still relied heavily on comparative costings to make decisions regarding OSP. In an investigation of several project cost comparisons between traditional and OSP options, compiled by cost consultants and contractors, it was found that all had significantly differing methods of evaluation (Blismas et al., 2004). All, but one, were purely cost-based in their comparisons. Common methods of evaluation simply took material, labour and transportation costs into account when comparing various options, disregarding other cost-related items such as site facilities, crane use and rectification of works. Often these cost factors were buried within the imprecise enabling works or preliminaries figures, with little reference to the approach. Further, softer issues such as health and safety, effects on management and process benefits were either implicit or disregarded within these comparison exercises. Apart from the poor build-up of cost figures, only one of these cases regarded any of the wider, softer issues involved with considering the benefits or value of OSP. A more holistic and thorough value-based comparative system was required by the industry to ascertain the true benefits of OSP for particular project settings. The toolkit sought to do this by building on previous work that identified drivers and constraints to OSP.

\section{Drivers and constraints}

Integrated within the toolkit are a series of factors that were derived by Gibb and Isack (2003) for a previous project, Standardisation and Pre-assembly - Clients Guide and Toolkit (CG\&T)2. Gibb and Isack used a series of rigorous focus groups and workshops involving experts from industry to identify a set of factors influencing the use of OSP. The positive influences evolved into a subset termed process 'drivers', while the negative influences were termed 'constraints'. Further workshops confirmed these subsets and their constituent factors. For ease of identification, both the drivers and constraints were further grouped into more descriptive categories. The final list of drivers, constraints and their groupings are listed in Table 1 below.

DRIVERS
Cost Drivers
D1 Ensuring project cost certainty
D2 Minimising non construction costs
D3 Minimising construction costs
D4 Minimising overall life cycle costs

\section{Time Drivers}

D5 Ensuring project completion date is certain

D6 Minimising on-site duration

D7 Minimising overall project time

\section{Quality Drivers}

D8 Achieving high quality

D9 Achieving predictability of quality

D10 Achieving performance predictability throughout the lifecycle of the facility

\section{Health and Safety Driver \\ D11 Reducing health and safety risks}

\section{Sustainability Drivers}

D12 Reducing environmental impact during construction

D13 Implementing Respect for People principles

D14 Maximising environmental performance throughout the lifecycle

\section{CONSTRAINTS}

\section{Site Constraints}

C1 Restricted site layout or space

C2 Multi trade interfaces in restricted work areas

C3 Limited or very expensive available skilled on-site labour

C4 A problem transporting manufactured products to site

C5 Live working environment limits site operation

C6 Limitation to movement of OSP units around site

$\mathrm{C} 7$ Site restricted by external parties

\section{Process Constraints}

C8 Short overall project time scales

C9 Unable to freeze design early enough to suite OSP

C10 Limited capacity of suppliers

C11 Not possible for follow-on projects to use the same processes C12 No opportunity for component repeatability on this or future projects

\section{Procurement Constraints}

C13 Project team members have no previous experience of OSP

C14 Obliged to work with a particular supply chain

C15 Not willing to commit to a single point supplier

C16 Obliged to accept lowest cost rather than best value

C17 Key decisions already made preclude OSP approach

C18 Limited expertise in off-site inspection

C19 Obliged to accept element costing based on SMM

C20 Early construction/manufacturing expertise \& advice unavailable

Table 1: List of drivers and constraints

\section{Structure and logic}

The drivers and constraints derived by Gibb and Isack (2003) formed the basis for further research that delved deeper into the components of value upon which judgements are made regarding OSP use on construction projects. The project adopted a variety of methods to ensure rigour and validity in the research. Development of the toolkit, through progressive conceptual designs, was aided by workshops involving construction professionals, contractors and clients. These focused workshops were also used to test the toolkit, refine the detailed content of the various tools, and to collect data from experts in industry. Four workshops were conducted over the life of the project, each drawing between 15 and 30 delegates from across the supply chain.

Further data was gathered through interviews, case studies and a questionnaire survey. The interviews explored the issues surrounding the measurement of OSP benefit. A snowball or rolling sampling method was used to interview and consult over fifty people from the entire supply-chain, including clients. A data collection matrix was used as a guide during the interviews to focus the discussions on specific aspects of the research. The survey, which is central to the development of the IAI, is detailed in the following section.

The toolkit comprises of three distinct tools, an introduction and information tool (IIT), an interactive benefit indicator tool (IBIT), and a benefit measurement tool (BMT). Each tool introduces increasing levels of detail and specificity to the project and element being evaluated. The first tool introduces the subject of OSP at a general level providing links and references to further important work. The second tool furnishes the user with a range of potential 
benefits and disbenefits for given project objectives. The third tool provides a template for users to build-up a comprehensive benefit evaluation profile for a particular building element of a project. This final tool aims to offer users a highly flexible means of conducting detailed comparative evaluations of several OSP building options. Incorporated within this third tool is a simple IAI that indicates a project's suitability to using an OSP approach. This paper focuses on this instrument within the third tool of the toolkit. Figure 1 illustrates the links between the various components of the toolkit.

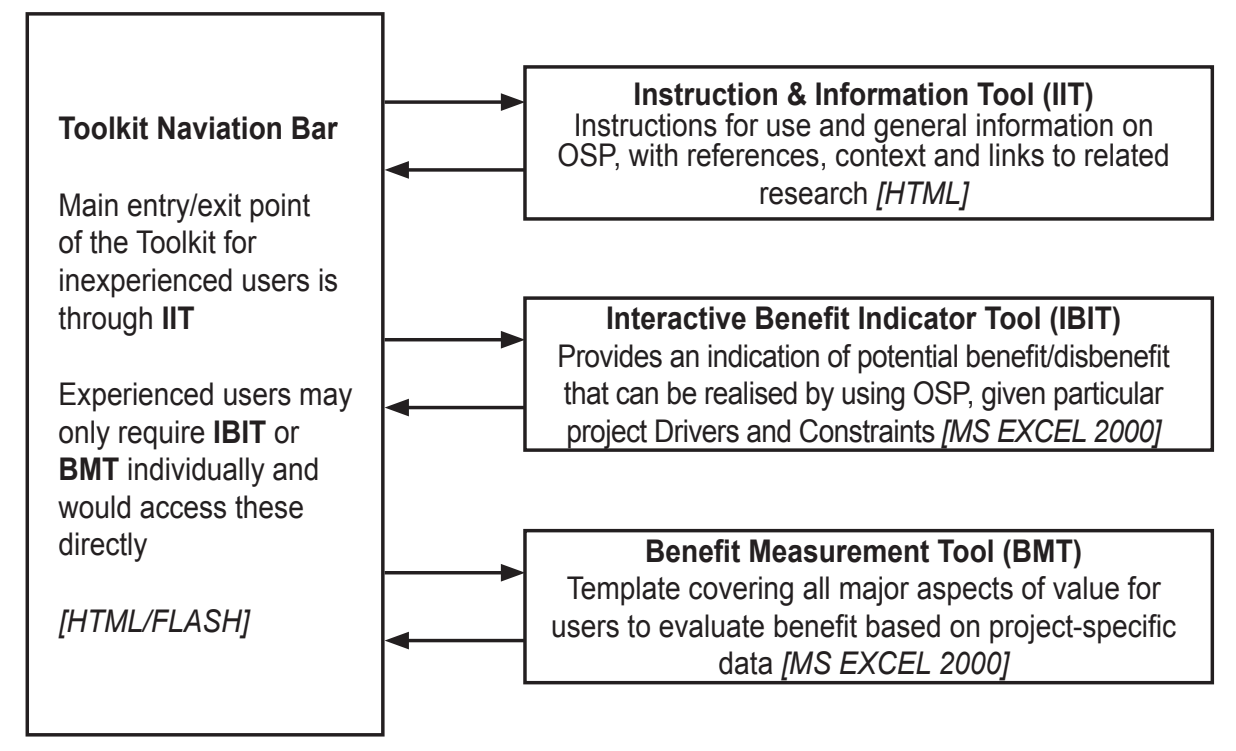

Figure 1: Schematic outline of the IMMPREST toolkit (SOURCE: Blismas et al., 2003b)

\section{CONSTRAINT SURVEY}

A questionnaire survey was undertaken to understand the particular areas within the broader construction process that constrain the implementation of OSP on building projects. The questionnaires comprised of the drivers and constraints listed in Table 1, against which respondents could indicate, on a Likert scale, their responses to the questions posed. Among the questions, respondents were asked what the likely impact was on using OSP for each of a given series of process and procurement constraints.
Two hundred and eighty nine (289) questionnaires were mailed in December 2002 to a sample comprising the IMMPREST project mailing list (Blismas et al., 2003b), Lean Construction Network mailing list, and the delegates of The Way Forward Conferences (Manufacturing the Future, 2002) ${ }^{3}$. Seventy three (73) replies were received, representing a $25.3 \%$ response rate. The responses were received from a wide spread of groups within the construction team, ranging from clients, consultants and through the entire supply-chain. Figure 2 illustrates the spread of responses according to roles within the industry. Significantly, the proportion of specialist suppliers was only $15 \%$, diminishing the possibility that the results were biased by their desires to portray OSP as a highly beneficial solution to construction projects.

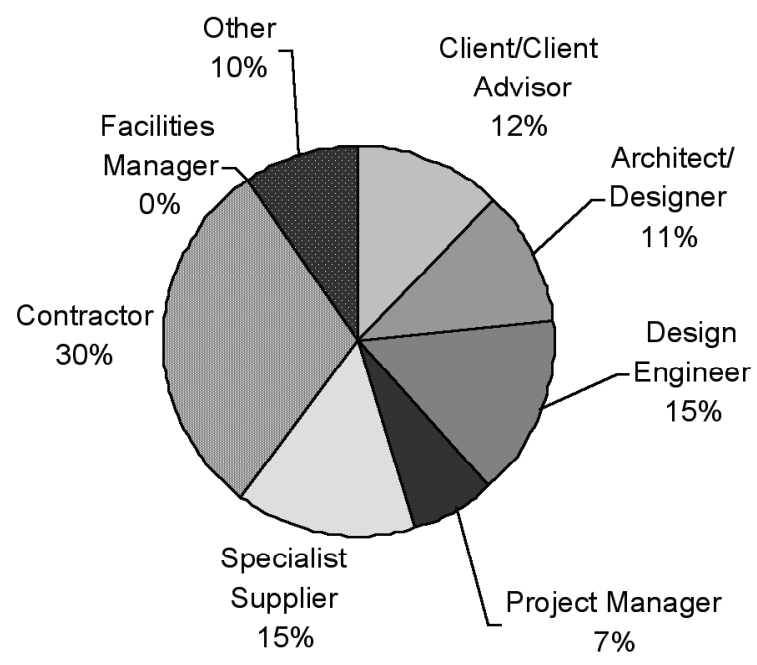

Figure 2: Chart illustrating the distribution of survey replies according to respondent's roles

A simple profile of respondent's experience with using OSP also revealed that approximately two-thirds had moderate to high experience of using OSP in construction. This majority ensured that the responses were based on actual experiences and not on expected outcomes that suppliers of OSP products claim. Figure 3 graphically depicts the level of experience with OSP by respondents. 


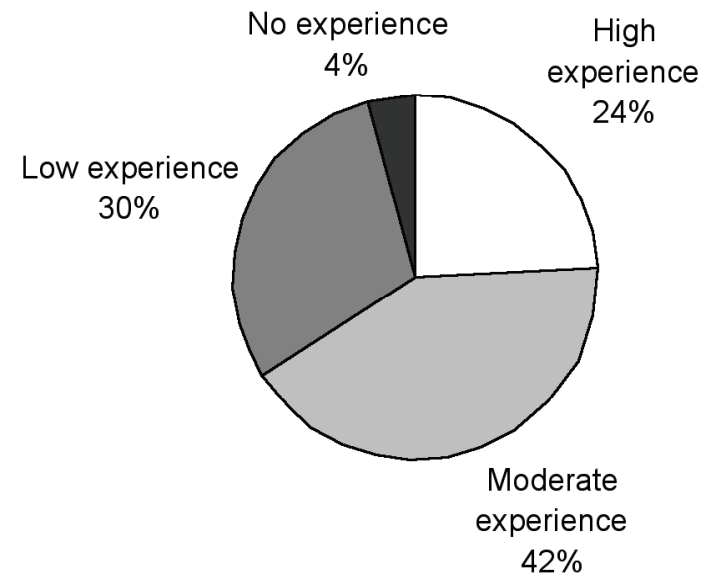

Figure 3: Chart illustrating the distribution of survey replies according to respondent's OSP experience

Reponses to the questions regarding the process and procurement constraint categories were scored according to the responses selected on the Likert scale. Table 2 provides the points used to score each constraint response. Each constraint was then ranked from lowest to highest scores, reflecting the constraints that most hinder OSP implementation. Using the scores derived from the questionnaire survey responses, the simple IAI was derived using a penalty score system.

\section{OSP IMPLEMENTATION ASSESSMENT}

The IAI was developed within the suite of tools in IMMPREST to provide project teams, but particularly clients and their advisors, with a quick assessment of their OSP implementation readiness. It is particularly suited to brainstorming and workshop settings where the implications of each constraint can be discussed and resolved. Once responses were scored using the figures in Table 2, the mean score for each constraint was calculated. This provided a method for ranking constraints according to their level of influence (Table 3, column a). These scores were then inverted to give the constraint that exerted the most influence on the highest score (Table 3, column b). Once ranked by score from highest (i.e. most constraining) to lowest score, a further formula was applied to arrive at a percentage penalty score for each constraint (Table 3 , column c).

\begin{tabular}{lc}
\hline Response from Questionnaire & Score \\
\hline Significant hindrance to using OSP & 1 \\
Moderate hindrance to using OSP & 2 \\
No impact & 3 \\
Moderate benefit to using OSP & 4 \\
Significant benefit to using OSP & 5 \\
\hline
\end{tabular}

Table 2: Scores used to allocate points against responses from the questionnaire survey for process and procurement constraints as defined in Table 1

\begin{tabular}{|c|c|c|c|}
\hline Constraint & $\begin{array}{c}\text { Ave Score } \\
\text { (a) }\end{array}$ & $\begin{array}{c}\text { Inverse } \\
5-(a) \\
\text { (b) }\end{array}$ & $\begin{array}{c}\text { (b) } / \sum(b) \\
\times 100 \\
\text { (c) }\end{array}$ \\
\hline 1. Unable to freeze design and specification early & 1.88 & 3.12 & 9.13 \\
\hline 2. Obliged to accept lowest cost rather than best value & 1.99 & 3.01 & 8.83 \\
\hline 3. Key decisions early in process preclude OSP & 2.04 & 2.96 & 8.66 \\
\hline 4. Unwilling to commit to single-point supplier & 2.16 & 2.84 & 8.32 \\
\hline 5. Limited previous OSP experience within team & 2.22 & 2.78 & 8.15 \\
\hline 6. Early advice unavailable & 2.23 & 2.77 & 8.11 \\
\hline 7. Limited choice of supply chain for project & 2.23 & 2.77 & 8.11 \\
\hline 8. Limited capacity of supplier(s) & 2.29 & 2.71 & 7.93 \\
\hline 9. Limited expertise in off-site inspection & 2.41 & 2.59 & 7.60 \\
\hline 10. Obliged to accept element-specific costing & 2.42 & 2.58 & 7.55 \\
\hline 11. Product or component repeatability not feasible & 2.45 & 2.55 & 7.46 \\
\hline 12. Difficult to re-use processes on new projects & 2.77 & 2.23 & 6.53 \\
\hline 13. Short project time-scales & 3.76 & 1.24 & 3.62 \\
\hline TOTALS & 30.86 & 34.14 & 100.00 \\
\hline
\end{tabular}

Table 3: Conversion of survey scores into penalty points for IAI 
The penalties were then worked-up into a simple, single page, visually engaging electronic instrument. Feedback from the extensive toolkit development workshops, undertaken with the UK construction industry, strongly influenced the appearance and structure of IMMPREST and IAI. It allows teams to easily and quickly identify key issues that would constrain the implementation of OSP on their projects. The IAI does not replace client advice provided by CIRIAs CG\&T, but aims to present an initial indicator of potential constraints that will need active steps to mitigate, if OSP is to be successfully implemented.

Within the IAI, each constraint is listed from highest penalty score to lowest, along with descriptions to aid those not familiar with terms used in the toolkit (see Figure 4). Users have three choices that can be made for each constraint, depending on the relevance of the constraint to the project under consideration. The selections that can be made by clicking the applicable radio button are 'Not Relevant', 'Maybe', and 'Definitely'. Selection of a constraint as 'Definitely' relevant for a project will return the full penalty score for the constraint. Should the constraint not be relevant to the project, selection of the appropriate button will return a zero penalty rating for that constraint. Where the relevance of the constraint is uncertain, and a 'Maybe' selection is made, a penalty score of $30 \%$ of the full figure is returned. A figure close to one third of the penalty was selected as this would better represent an undecided situation, implying that a change to the situation was still possible. Table 4 indicates the scores that each relevance choice would return.

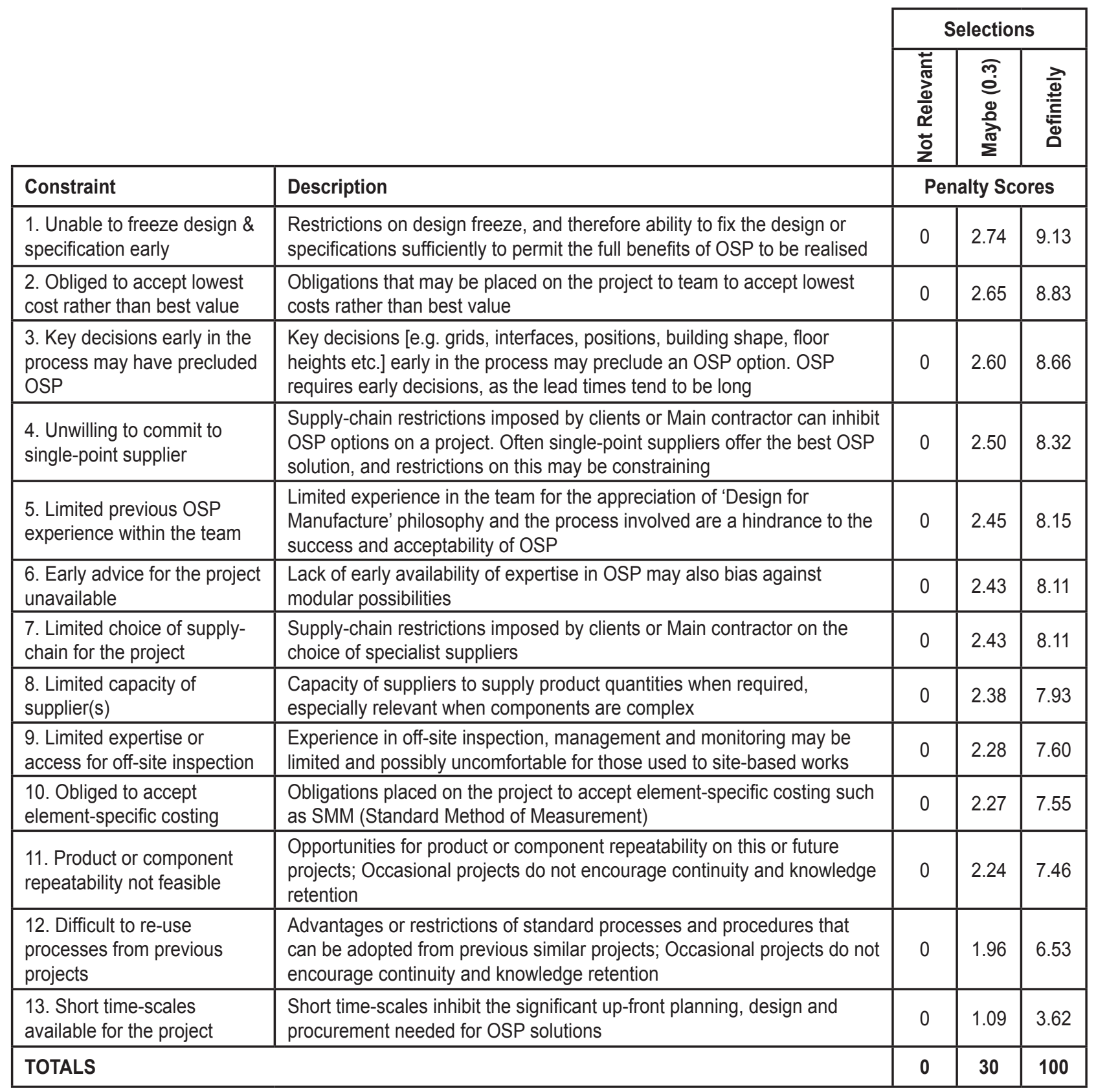

Table 4: Information and scoring system contained within the IAI

A cumulative penalty score at the bottom of the table provides a quick overall assessment of the project's OSP implementation 'readiness'. High penalty scores would indicate that the situation would not be conducive to OSP implementation and would probably result in failure. An intuitive score assessment was used that would again encourage uncertain project teams to work towards OSP constraint mitigation. The advice provided with the IAl for the cumulative score total is of a broad and general nature (Table 5). This is in keeping with feedback from the industrial workshops, in which delegates generally opposed highly specific and often meaningless toolkit outcomes, especially with qualitative assessments. 


\begin{tabular}{ll}
\hline Penalty & Interpretation of Points \\
\hline $0-30$ & Project conditions are highly suited to OSP \\
$31-70$ & $\begin{array}{l}\text { OSP should still provide benefits to the project } \\
71-100\end{array}$ \\
$\begin{array}{l}\text { Project may not be suitable for OSP, however this } \\
\text { option should still be assessed }\end{array}$ \\
\hline
\end{tabular}

Table 5: Simple advice given in the toolkit for cumulative penalty scores

Colour-coding is a feature that was strongly advocated by workshop delegates during the developmental stages of the toolkit. A simple green, amber, red system is used to indicate penalty levels for each constraint, allowing a quick-scan of the most inhibiting factors. Likewise the final cumulative score is colour-coded corresponding to the three advice bands of Table 5 . Figure 4 is a screenshot of the tool indicating many of the features discussed above.

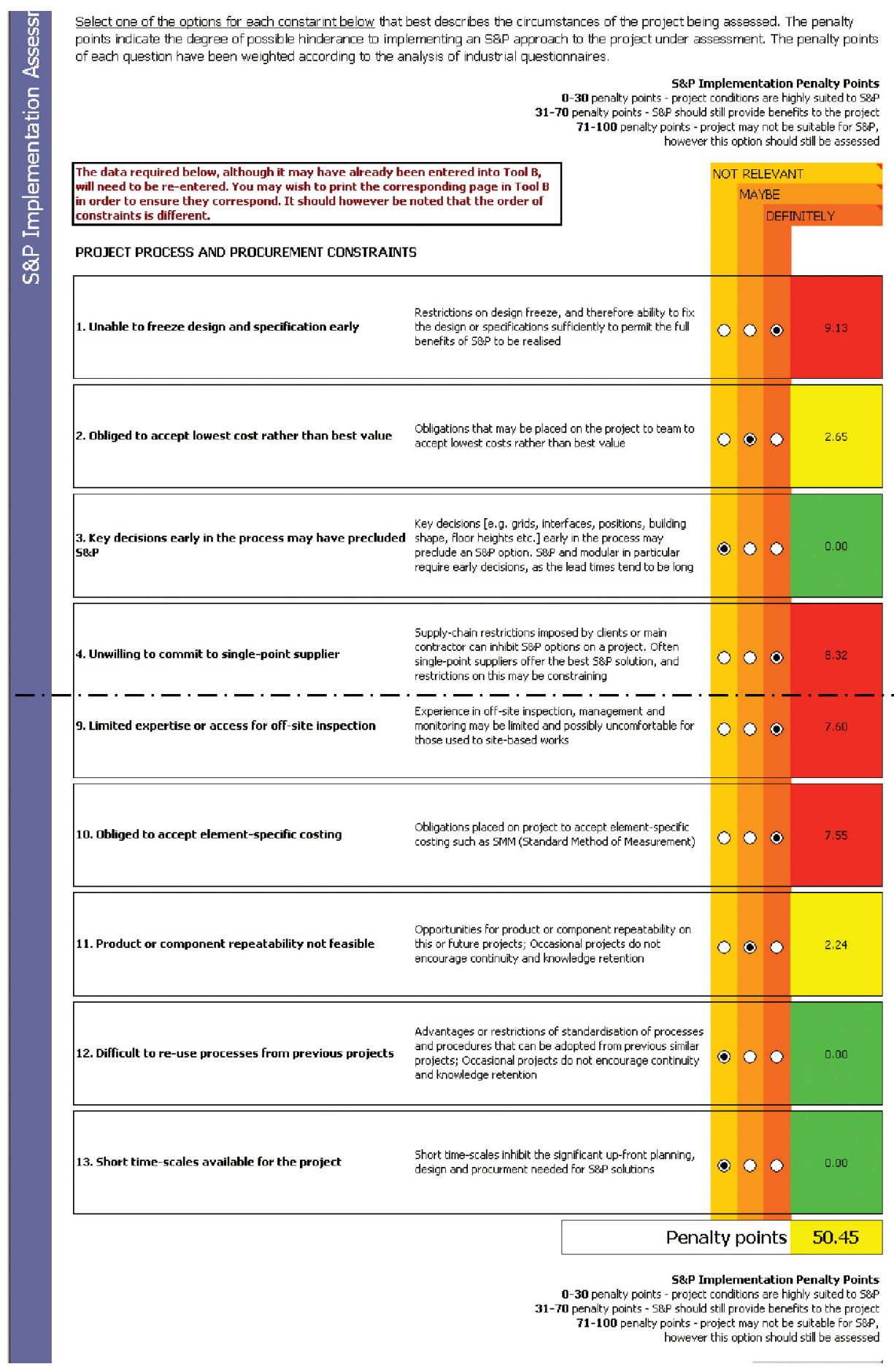

Figure 4: Screenshot of the OSP implementation assessment instrument 


\section{"CONCLUSIONS}

Off-site production has been widely promoted as a means of improving construction performance and transforming it into a modern, safe and efficient industry. However, implementation of OSP has been slow and erratic due, in part, to process and procurement constraints inherent within most construction projects. Wider OSP adoption therefore requires an increased awareness by clients and construction project teams of the benefits and constraints associated with such an approach. IMMPREST and the CG\&T were developed to facilitate this evaluation process, and thus encourage greater OSP investigation and uptake.

One particular aspect of the toolkit, the IAI was developed as a simple measure of client and project suitability to OSP adoption. A number of process and procurement constraints were shown to inhibit OSP adoption, many of which are in the direct control of construction clients. This paper therefore argues that clients need to be engaged to a greater extent if the promotion of OSP in construction is to succeed. Unless the consequences of client procurement and professional team selections are highlighted, project environments will not become conducive to greater OSP adoption. The assessment tool described in this paper assists in focussing clients and their advisors on aspects which may inhibit OSP adoption and success. Such focus allows client teams to mitigate the constraints and thereby ease the way for greater OSP use on construction projects.

\section{REFERENCES}

Blismas, N.G., Pasquire, C.L., Gibb, A.G.F. and Aldridge, G.B. (2003a), IMMPREST - Interactive Method for Measuring Preassembly and Standardisation benefit in construction, (CD format), Loughborough University Enterprises Limited, Loughborough University, UK, ISBN 0-947974-13-X.

Blismas, N.G., Gibb, A.G.F., Pasquire, C.L. and Aldridge, G. (2003b), 'Changing perceptions of value in construction standardisation and pre-assembly', in proceedings of 2nd International Conference on Innovation in Architecture, Engineering and Construction, 25-27th June, Loughborough University, UK.

Blismas N.G, Pasquire C.L, Gibb A.G, (2004), 'Benefit evaluation for off-site production in construction', submitted to Construction Management and Economics.

Bottom, D., Gann, D., Groak, S. and Meikle, J. (1994), Innovation in Japanese prefabricated house-building industries, report sponsored by Construction Industry Research and Information Association (CIRIA) and Department of Trade and Industry, London.

BSRIA (1999), Prefabrication and Preassembly - applying the techniques to building engineering services, compiled by Wilson, D.G., Smith, M.H. and Deal, J., Advanced Construction Techniques ACT 1/99 report of The Building Services Research and Information Association, United Kingdom.

CIRIA (1999), Adding Value to Construction Projects through Standardisation and Pre-assembly, compiled by Gibb, A.G.F., Groák, S., Neale, R.H. and Sparksman, W.G., Report R176, Construction Industry Research and Information Association, London.

CIRIA (2000), Standardisation, Pre-assembly and Modularisation - A Client's Guide, Construction Industry Research Information Association, London.
Egan, J. (1998), Rethinking Construction, The Egan Report, Department of the Environment, Transport and the Regions.

Gibb, A.G.F. (2001), 'Standardisation and pre-assembly distinguishing myth from reality using case study research', Construction Management and Economics, vol.19, pp.307-315.

Gibb, A.G.F. and Isack, F. (2003), 'Re-engineering through preassembly: client expectations and drivers', Building Research and Information, vol.31, no.2, pp.146-160.

Groák, S. (1992), The Idea of Building, E\&FN Spon/Routledge, London.

Housing Forum (2002), Homing in on excellence: A commentary on the use of off-site fabrication methods for the UK housebuilding industry, a report of the Housing Forum, London.

Neale, R., Price, A. and Sher, W. (1993), Prefabricated modules in construction: a study of current practice in the United Kingdom, The Chartered Institute of Building, United Kingdom.

Pasquire C.L. and Gibb A.G.F. (1999), Considerations for Assessing the Benefits of Standardisation and Pre-assembly in Construction (the Findings of a Pilot Study), report to CIBSE Seminar on Standardisation in the Design and Construction of Building Services Installations, 26 October 1999.

\section{ENDNOTES}

${ }^{1}$ Off-site production (OSP) can be defined as the completion of substantial parts of 'construction' works prior to their installation onsite. It replaces previously common terms such as pre-assembly and pre-fabrication. There are numerous levels of OSP, from preassembled sub-elements to whole buildings. A further discussion of these levels is given by Gibb and Isack (2003).

${ }^{2}$ Deliverable for a UK Government funded research project (CIRIA, 2000).

${ }^{3}$ The Way Forward for off-site construction in the health, social housing and education sectors. Organised by Manufacturing Change, National Motorcycle Museum, Solihull. 5-7 November 2002. 